DOI: https://doi.org/10.24867/08BE37Ivanovic

\title{
STUDIJA PODEŠENJA ELEKTRIČNIH ZAŠTITA TRANSFORMATORSKE STANICE 33/220kV VETROELEKTRANE KOVAČICA
}

\section{STUDY OF RELAY PROTECTION SETTINGS FOR POWER SUBSTATION 33/220kV KOVAČICA WIND FARM}

\author{
David Ivanović, Fakultet tehničkih nauka, Novi Sad
}

\begin{abstract}
Oblast - ELEKTROTEHNIKA I RAČUNARSTVO
Kratak sadržaj - U ovom radu je rađena studija podešenja relejne zaštite na jednom savremenom projektu od velike važnosti za elektroenergetski sistem Srbije vetroelektrana „Kovačica“. Detaljno je odrađen proračun podešenja zaštitnih funkcija vetroelektrane u $220 \mathrm{kV}$ postrojenju na zaštiti energetskih transformatora. Zatim zaštita u $33 \mathrm{kV}$ postrojenju na transformatorskim ćelijama, izvodnim ćelijama ka vetrogeneratorima i spojnim ćelijama su prikazana. Svi neophodni tehnički podaci kao i kratak opis vetroelektrane su dati. Odrađen je i opisan proračun podešenja a na osnovu tehničkih preporuka, tipskih podešenja, odgovarajućih tehničkih uptstava dobijeni su krajnji rezultati koji su tabelarno predstavljeni.

Ključne reči: Relejna zaštita, Zaštitne funkcije, Parametri
\end{abstract}

Abstract - This paper deals with the study of relay protection settings on a modern project of great importance for the power system of Serbia - wind farm „Kovačica“. The calculation of the settings of wind power protection functions in a $220 \mathrm{kV}$ switchyard on the protection of power transformers has been done in detail. Subsequently, protection in $33 \mathrm{kV}$ switchgears on transformer switcgears, feeder switcgears to wind turbine generators and connection switchgears are shown. All the necessary technical data as well as a brief description of the wind farm are given. The calculation of the settings was made and described, and based on the technical recommendations, type settings, corresponding technical instructions and final results were presented in tables.

Keywords: Relay protection, Protection functions, Parameters

\section{UVOD}

Elektroenergetski sistem je skupa investicija koja treba da se dizajnira, sprovede i upravlja sa velikom opreznošću tako da pruži pouzdano i sigurno rešenje. Transformatorske stanice i razvodna postrojenja su jedna od komponenti investicija koja zahtevaju detaljan inženjerski rad od faze dizajniranja do faze implementacije. Ako odgovarajući dizajn sistem zaštite ne sledi, struje kvara abnormalnih stanja u par sekundi mogu da oštete komponente tih velikih investicija. Prema tome, tokom dizajniranja potrebno je da se izvrši detaljna analiza sistema.

\section{NAPOMENA:}

Ovaj rad proistekao je iz master rada čiji mentor je dr Duško Bekut, red. prof.
$\mathrm{Na}$ osnovu rezultata analiza, sistem zaštite, opema i tehnika treba ispravno da se definiše pre faze implementiranja. To uključuje selekciju odgovarajućih prekidača, osigurača, izolatore, merne transformatore, zaštitne releje i tako dalje.

Štaviše, pravilna koordinacija među tom opremom je presudan zadatak koji treba da izvrše inženjeri zaštite $i$ upravljanja. U ovom radu izvršen je detaljan proračun i implementacija relejne zaštite na konkretnoj savremenoj transformatorskoj stanici vetroparka. Selekcija odgovarajuće zaštitne opreme je jedna od ključnih koraka za ispravno funkcionisanje relejne zaštite. U drugoj glavi opisane su zaštitne funkcije glavne zaštite, uređaj za automatsku regulaciju napona i rezervne zaštita u $220 \mathrm{kV}$ postrojenju. U trećoj glavi opisane su funkcije zaštita na $33 \mathrm{kV}$ postrojenju na transformatorskim, izvodnim i spojnim ćelijama. Izvršen je proračun i određeni su parametri podešenja prikazani tabelarno na kraju rada. $U$ petoj glavi data je korišćena literatura.

\section{ZAŠTITNI UREĐAJI I PRORAČUN PODEŠENJA TRANSFORMATORSKIH POLJA U 220 kV POSTROJENJU}

Ovim delom obuhvaćeni su sledeće dve zaštite i njihove zaštitne upravljačke funkcije od kojih će samo neke biti opisane u nastavku u ovom radu:

Glavna zaštita (F302) transformatora je tipa ABB RET670 i sadrži sledeće zaštitne funkcije:

- $87 \mathrm{~T}$ Diferencijalna zaštita transformatora.

- $\quad 87 \mathrm{~N}$ Ograničena zemljospojna zaštita (Visokonaponska strana u daljem VN strana).

- 50/51 Prekostrujna i kratkospojna zaštita (VN strana).

- $46 \quad$ Zaštita od nesimetričnog opterećenja.

- $51 \mathrm{~N} Z$ Zemljospojna zaštita (VN strana).

Uređaj za automatsku regulaciju napona $i$ rezervna zaštita (A202) je tipa ABB RET650 i sadrži sledeće zaštitne i upravljačke funkcije:

- $87 \mathrm{~T}$ Diferencijalna zaštita transformatora.

- $\quad 87 \mathrm{~N}$ Ograničena zemljospojna zaštita (Niskonaponska strana u daljem NN strana).

- $51 \quad$ Prekostrujna zaštita (NN strana).

- 51 Prekostrujna zaštita neutrale $33 \mathrm{kV}$.

- 90; 84 Automatska regulacija napona; Upravljanje i nadzor regulacione preklopke. 


\section{Diferencijalna zaštita (87T)}

Diferencijalna zaštita, uz Buholc i ograničenu zemljospojnu zaštitu, predstavlja osnovnu zaštitu energetskog transformatora $220 / 33 \mathrm{kV}$ - slika 1 .

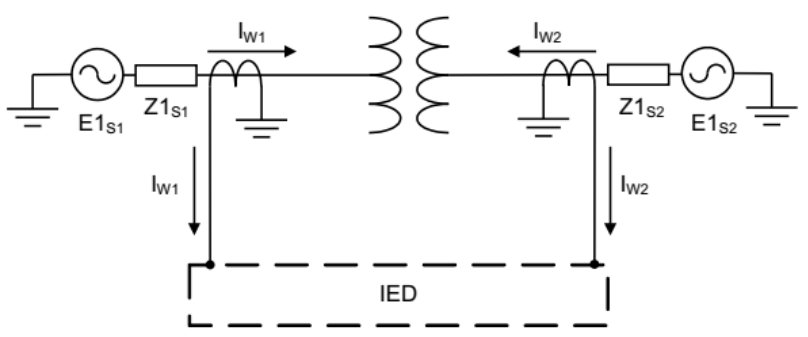

Slika 1 - Shema diferencijalne zaštite transformatora

Algoritam diferencijalne zaštite obavlja normalizaciju prenosnog odnosa strujnih mernih transformatora, kompenzaciju faznog pomeraja, kao i stabilizaciju uticaja viših harmonika struje magnetizacije. Algoritam sadrži i napredni diskriminator spoljnih i unutrašnjih kvarova na osnovu merenja struje inverzne komponente.

Diferencijalna zaštita ima dva stepena (slika 2):

stabilisani (niži stepen, restrained) $-I_{d}>$,

nestabilisani (brzi, viši stepen, unrestrained) -

$I_{d} \gg$.

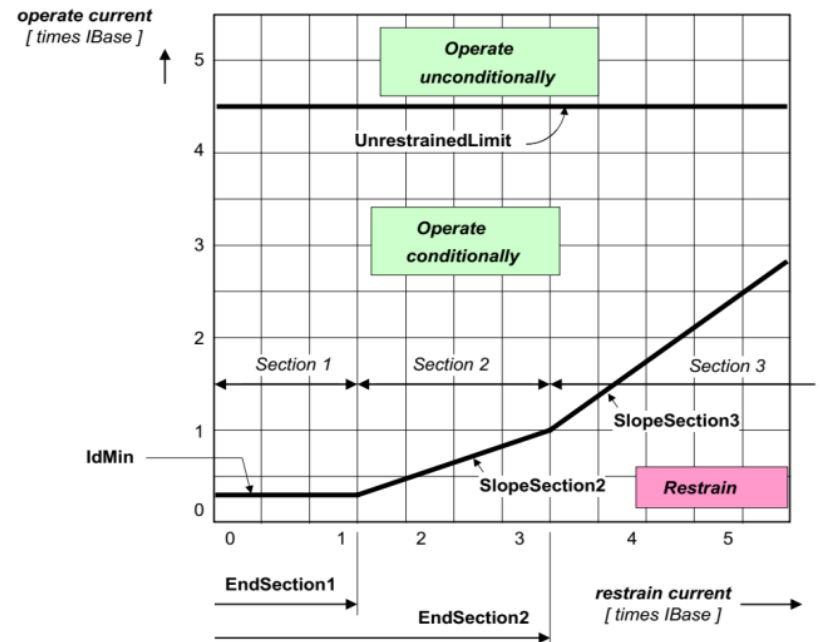

Slika 2 - Karakteristika diferencijalne zaštite transformatora

Podešavanje diferencijalne struje prorade definiše se kao procenat bazne struje ( $I_{\text {Base }}$, definiše se zajedno sa baznim vrednostima napona i prividne snage, $V_{\text {Base }}$ i $S_{\text {Base }}$, u okviru grupe podešenja Global base values). Za vrednost bazne struje se usvaja nominalna struja transformatora (na VN strani). Stabilisani stepen ima takvu karakteristiku (slika 2, donja karakteristika) da je diferencijalna struja prorade $\left(I_{d}\right)$ zavisna od stabilizacione struje $\left(I_{\text {bias }}\right)$, pri čemu se vrednosti ovih struja određuju na sledeći način:

$$
\begin{gathered}
I_{d}=\left|\underline{I}_{1}+\underline{I}_{2}\right| \\
I_{\text {bias }}=\max \left(\left|\underline{I}_{1}\right|,\left|\underline{I}_{2}\right|\right)
\end{gathered}
$$

gde $\underline{I}_{1}$ i $\underline{I}_{2}$ predstavljaju struje pojedinačnih namotaja transformatora. Karakteristika se sastoji iz tri sekcije, jedne horizontalne $\left(I_{d M i n}\right)$ i dve pod nagibom (SlopeSection2, SlopeSection3) i definiše se uz pomoć parametara $I_{d M i n}$, EndSection1, EndSection2, SlopeSection2, SlopeSection3.

Kod podešenja minimalne proradne struje $I_{d M i n}$ uzima se u obzir greška koju unose strujni merni transformatori (koja je relativno mala u slučaju male vrednosti diferencijalne struje u početnom delu karakteristike) kao i greška koju unosi regulaciona sklopka (ukoliko se informacija o položaju sklopke ne dovodi u zaštitni uređaj, što je ovde slučaj). Podešenje minimalne proradne struje zavisi od tipa energetskog transformatora, u ovom slučaju transformator sa regulacijom pod opterećenjem, preporuka proizvođača zaštitnog uređaja za podešenje parametra $I_{d M i n}$ a i EMS-ova dosadašnja praksa za transformatore sa regulacijom pod opterećenjem je $\Delta \mathrm{I}=30 \%$.

U okviru sekcije 2, vrednosti struja transformatora su veće od nominalnih i greška koju unose strujni merni transformatori je srazmerno veća, te je i proradna vrednost diferencijalne struje veća i povećava se sa porastom stabilizacione struje. U okviru sekcije 3, ova greška je još više izražena jer dolazi do potencijalnog zasićenja strujnih transformatora, pa je i nagib karakteristike veći nego u drugoj sekciji. Za podešenja parametara duge i treće sekcije karakteristike stabilisanog stepena, usvajaju se preporuke proizvođača zaštitnog uređaja. Delovanje diferencijalne zaštite transformatora je trenutno. Na slici 3 je prikazana zona delovanja diferencijalne zaštite transformatora, kao i zone delovanja ostalih zaštita od međufaznih kvarova $u$ postrojenjima $220 \mathrm{kV}$ i $33 \mathrm{kV}$.

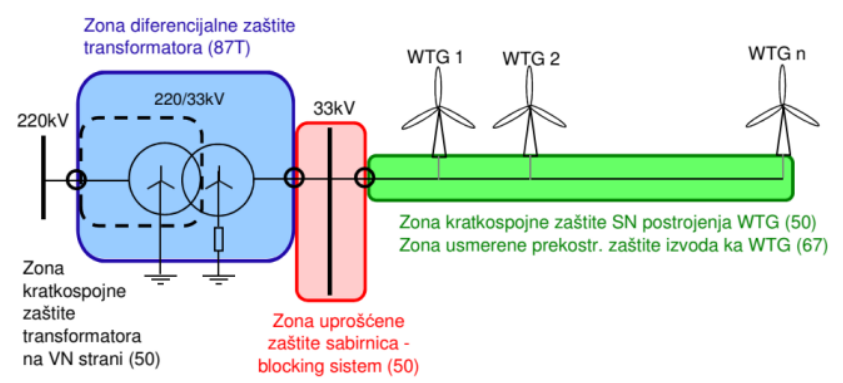

Slika 3 - Zone delovanja diferencijalne zaštite i zaštita od međufaznih kvarova u postrojenjima $220 \mathrm{kV}$ i $33 \mathrm{kV}$

Karakteristika nestabilisanog stepena $\left(I_{d} \gg\right)$ diferencijalne zaštite je horizontalna i definiše se kao procenat bazne struje $\left(I_{\text {Base }}\right)$, bez uticaja stabilizacione struje. Ova karakteristika se koristi za veoma visoke vrednosti diferencijalne struje, za koje se sa sigurnošću može tvrditi da su posledica unutrašnjeg kvara transformatora.

Podešenje ovog stepena treba izabrati tako da bude ispunjen uslov:

$$
\left(I_{d} \gg\right)<I_{3 K S}^{\prime}=\frac{c \cdot U_{L}}{\sqrt{3} \cdot\left(Z_{m 220}+Z_{T R 220}\right)}
$$

gde su:

$I_{3 K S}^{\prime}$ - struja tropolnog kratkog spoja na VN strani transformatora,

$Z_{m 220}$ - ekvivalentna impedansa mreže $220 \mathrm{kV}$,

$Z_{T R 220}$ - impedansa transformatora na $220 \mathrm{kV}$ strani. 


\section{Ograničena zemljospojna zaštita $(87 \mathrm{~N})$}

Ograničena zemljospojna zaštita (engl. Restricted Earth Fault protection - REF) deluje u slučaju zemljospoja na štićenom namotaju transformatora. Naziva se i diferencijalna zemljospojna zaštita a diferencijalna zona njenog delovanja jeste između strujnog transformatora $u$ zvezdištu štićenog namotaja i tri strujna transformatora $u$ fazama datog namotaja energetskog transformatora. Može se primeniti i u slučaju direktno uzemljene neutrale transformatora (slika 4), ali i u slučaju uzemljenja preko otpornika za ograničenje struje zemljospoja. Tako se ova zaštita može primeniti za zaštitu od zemljospoja unutar namotaja transformatora $\mathrm{i}$ na $\mathrm{VN} i \mathrm{i}$ na $\mathrm{NN}$ strani energetskog transformatora $220 / 33 \mathrm{kV}$ u TS Kovačica.

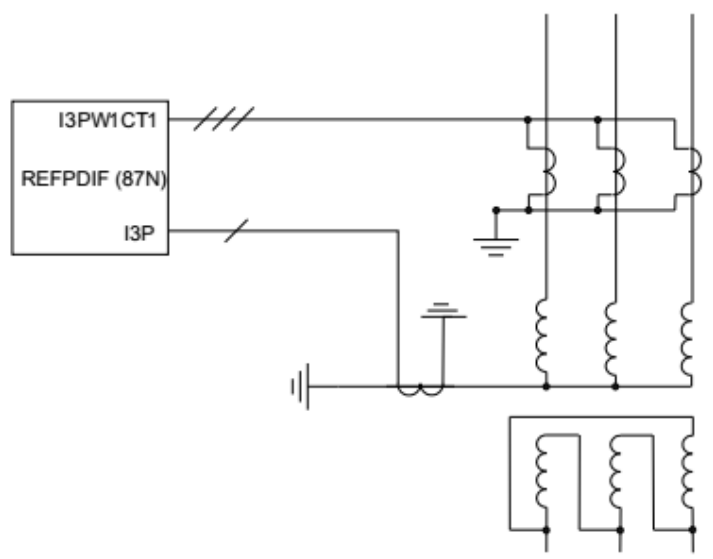

Slika 4-Primena REF zaštite u slučaju direktno uzemljene neutrale transformatora

$\mathrm{Na}$ slici 5 je prikazana zona delovanja REF zaštite transformatora, kao i zone delovanja ostalih zaštita od zemljospojeva u postrojenjima $220 \mathrm{kV}$ i $33 \mathrm{kV}$.

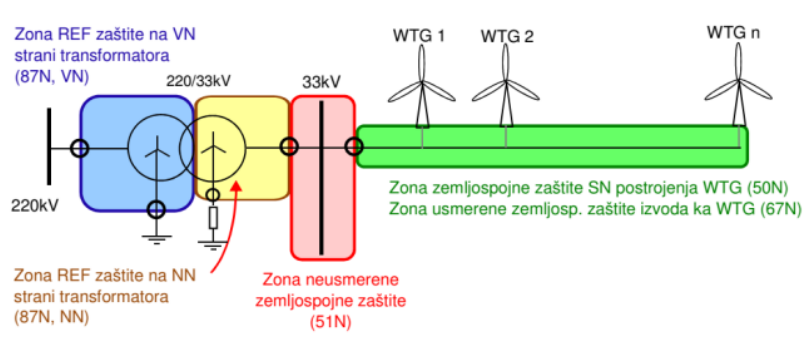

Slika 5 - Zone delovanja zaštita od zemljospojeva u postrojenjima $220 \mathrm{kV}$ i $33 \mathrm{kV}$

\section{Prekostrujna zaštita (51)}

Prekostrujna zaštita se koristi kao rezervna zaštita za diferencijalnu zaštitu i obezbeđuje zaštitu od kvarova u mreži. Trebalo bi je podestiti tako da obezbedi privremeno preopterećenje transformatora tokom ograničenog vremenskog perioda. Uzimajući u obzir da je dozvoljeni faktor preoptrećenja prema IEC standardu $20 \%$, za proradnu vrednost prekostrujne zaštite se uzima:

$$
I>=1,2 \cdot I_{n T R}
$$

Vreme zatezanja se podešava na vrednost veću za jedan vremenski interval $(t=0,3-0,4 s)$ od vremena isključenja prekostrujne zaštite NN strane. Na slici 6 je prikazan koncept podešavanja vremena isključenja prekostrujnih zaštita u postrojenjima $220 \mathrm{kV}$ i $33 \mathrm{kV}$.

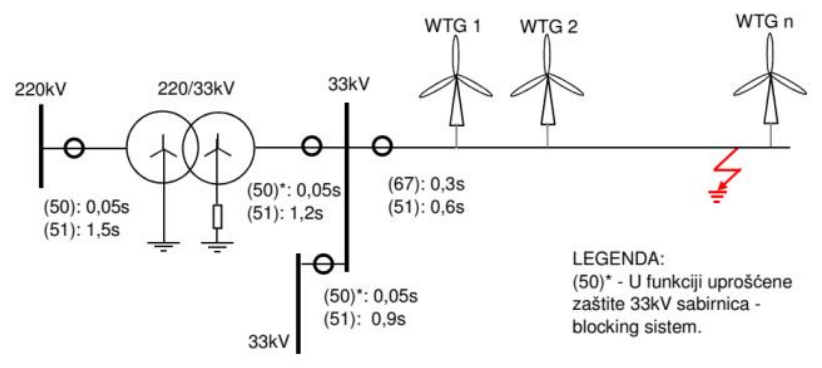

Slika 6-Podešenja vremena isključenja prekostrujnih zaštita u postrojenjima $220 \mathrm{kV}$ i $33 \mathrm{kV}$

\section{ZAŠTITNI UREĐAJI I PRORAČUN PODEŠENJA U 33 kV POSTROJENJU}

Uređaj zaštite i upravljanja transformatorskih ćelija je tipa ABB REF620 i sadrži sledeće zaštitne funkcije:

- 50/51 Prekostrujna i kratkospojna zaštita,

- $51 \mathrm{~N}$ Zemljospojna zaštita,

- 50BF Zaštita od otkaza prekidača.

\section{Kratkospojna zaštita (50)}

Prema tehničkom uputstvu za zaštite transformatora (Elektroistok, TU-ZA-03/2) za gornju granicu podešavanja struje kratkospojne zaštite na NN strani energetskih transformatora, koristi se sledeća relacija:

$$
\begin{gathered}
I \gg_{\max } \leq k_{r} \cdot I_{3 K S}^{\prime \prime} \\
I_{3 K S}^{\prime \prime}=\frac{c \cdot U_{L}}{\sqrt{3} \cdot Z_{e k v}^{\prime \prime}}=\frac{c \cdot U_{L}}{\sqrt{3} \cdot\left(Z_{m 33}+Z_{T R 33}\right)}
\end{gathered}
$$

gde su $k_{r}$ - koeficijent rezerve, za koji se uzima vrednost $k_{r}=0,6, I_{3 K S}^{\prime \prime}-$ struja tropolnog kratkog spoja na NN strani transformatora, $Z_{m 33}$ - ekvivalentna impedansa mreže na $33 \mathrm{kV}$ sabirnicama, $Z_{T R 33}$ - impedansa transformatora na $33 \mathrm{kV}$ strani.

Vrednost podešenja treba da zadovolji dva kriterijuma:

1) da je podešena struja veća od najveće vrednosti podešenih struja reagovanja kratkospojne odn. usmerene prekostrujne zaštite na izvodima $33 \mathrm{kV}$.

2) da je podešena vrednost veća od trostruke vrednosti nominalne struje odgovarajućeg namotaja energetskog transformatora.

Vreme zatezanja se podešava na vrednost $t_{I}>=0,05 \mathrm{~s}, \mathrm{~s}$ tim što je kratkospojna zaštita blokirana od pobude usmerene prekostrujne zaštite u svim izvodnim ćelijama $u$ $33 \mathrm{kV}$ postrojenju, u okviru iste sekcije.

\section{Izvodne ćelije ka vetrogeneratorima}

Srednje naponska mreža vetroelektrane je izvedena kao radijalna struktura s povezivanjem grupe od pet do sedam vetrogeneratora preko jednog zajedničkog kabla na srednjenaponsko postrojenje $33 \mathrm{kV}$ u okviru TS $33 / 220 \mathrm{kV}$ Kovačica. Takav način povezivanja smanjuje 
raspoloživost pogona vetroelektrane u slučaju kvara kabla, ali je ukupna dužina SN mreže manja.

$\mathrm{U}$ okviru transformatorske ćelije $33 \mathrm{kV}$ SN postrojenja na samom vetrogeneratoru, realizovane su sledeće zaštitne funkcije:

Podešenja zaštita na vetrogeneratorima:

- Prekostrujna zaštita (51) I>, IDMT,

- Kratkospojna zaštita (50) I $>>$,

- Zemljospojna zaštita $(51 \mathrm{~N}) \mathrm{I} 0>$.

Uređaj zaštite i upravljanja na izvodnim ćelijama je tipa ABB REF620 i sadrži sledeće zaštitne funkcije:

- 51 Prekostrujna zaštita,

- 67 Usmerena prekostrujna zaštita,

- $67 \mathrm{~N}$ Usmerena zemljospojna zaštita,

- 50BF Zaštita od otkaza prekidača.

\section{Proračun podešenja}

Za izvođenje predmetnih deonica kablovskih vodova ka vetrogeneratorima odabrani su jednožilni vodonepropusni kablovi tipa XHE 49-A ((N)A2XS(FL)2Y) 20,8/36/42kV. Kablovi su preseka od $150 \mathrm{~mm} 2$ do $500 \mathrm{~mm} 2$, zavisno od mesta deonice polaganja. $\mathrm{Na}$ osnovu podataka vezanih za impedanse kablova i na osnovu poznatih dužina kablovskih trasa po strujnim krugovima kao i vrednosti ekvivalentne impedanse mreže na sabirnicama $33 \mathrm{kV}$, dobijaju se struje kratkih spojeva po strujnim krugovima, na mestu svakog pojedinog vetrogeneratora, prema izrazu:

$$
I_{k s}=\frac{c \cdot U_{L}}{\sqrt{3} \cdot \sqrt{\left(R_{m 33}+R_{T R 33}+R_{d}\right)^{2}+\left(X_{m 33}+X_{T R 33}+X_{d}\right)^{2}}}
$$

gde su $R_{d}$ i $X_{d}$ rezistansa i reaktansa ukupnih kablovskih deonica do mesta kvara tj. do svakog pojedinačnog vetrogeneratora, a za naponski koeficijent se uzima $c=1$, pošto nam je potrebna minimalna vrednost struje kratkog spoja. Kratkospojna zaštita u izvodnoj ćeliji $33 \mathrm{kV}$ ne bi trebalo da reaguje u slučaju kratkog spoja na $6 \mathrm{kV}$ strani blok transformatora na vetrogeneratoru. Za proračun ove struje kratkog spoja $\left(I_{k s}, 6 \mathrm{kV}\right)$, u obzir se uzima i impedansa kratkog spoja blok transformatora 33/6/0,69kV i dodaje u gornji izraz (u deo za ukupnu reaktansu). Za vrednost naponskog faktora se uzima $c=1,1$, s obzirom da nam je potrebna maksimalna vrednost struje kratkog spoja.

\section{Zaštita od otkaza prekidača (50BF)}

Zaštita od otkaza prekidača radi na principu merenja struje kroz zaštitni uređaj i ako je ta struja iznad nekog podešenog praga posle isteka određenog vremena nakon izdavanja naloga za isključenje od neke zaštitne funkcije, generiše se signal otkaza prekidača. Takođe, radi sigurnosti, uređaj bi trebalo da proverava i status kontakata prekidača nakon izdavanja signala za isključenje. Svaka zaštitna funkcija koja šalje signal za isključenje bi trebalo da startuje i zaštitu od otkaza prekidača. Na slici 7 ispod se može videti logički dijagram.
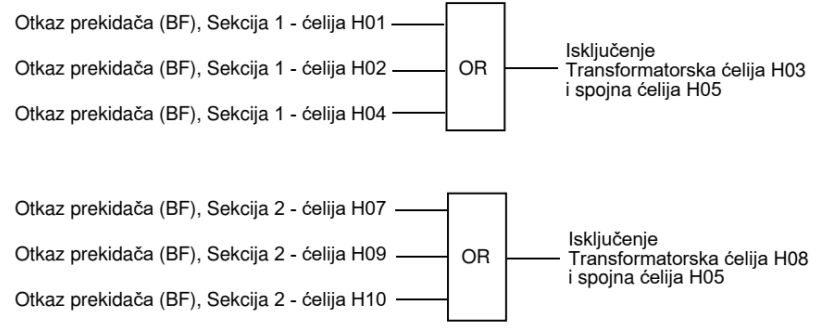

Slika 7 - Logički dijagram zaštite od otkaza prekidača

Svaka zaštitna funkcija koja šalje signal za isključenje bi trebalo da startuje i zaštitu od otkaza prekidača.

\section{Zaštita spojne ćelija i dodatak spojne ćelije}

Uređaj zaštite i upravljanja je tipa ABB REF620 i sadrži sledeće zaštitne funkcije:

- 50/51 Prekostrujna i kratkospojna zaštita,

- $51 \mathrm{~N}$ Zemljospojna zaštita,

- 50BF Zaštita od otkaza prekidača,

čiji je princip podešenja sličan prethodnim primerima.

\section{ZAKLJUČAK}

$\mathrm{U}$ radu je realizovana detaljna studija podešenja relejne zaštite tranformatorske stanice $33 / 220 \mathrm{kV}$ vetroelektrane Kovačica. Transformatorska stanica i razvodna postrojenja su jedna od velikih investicija čiji elementi zahtevaju sigurnu i pouzdanu zaštitu. Detaljno je prikaza postupak testiranja i puštanja relejne zaštite nakon čega je moguće vetropark uspešno priključiti kao aktivan na elektroenergetski sistem.

\section{LITERATURA}

[1] IEE d.o.o: Sveska 4.1- Projekat elektroenergetskih instalacija Transformacija 33/220kV I RP $33 k V$, Projektna sveska, Novi Sad, 2018.

[2] IEE d.o.o: Sveska 4.5 Sistem zaštite $i$ upravljanja, Projektna sveska, Novi Sad, 2018.

[3] IEE d.o.o: Sveska 4.6-Projekat elektroenergetskih instalacija-Upravna zgrada, Projektna sveska, Novi Sad, 2018.

[4] Log Design d.o.o.: Sveska 4.7 Projekat EE $i$ TK kablova za povezivanje vetroturbina, Projektna sveska, Beograd, 2018.

[5] Javno Preduzeće Elektromreža Srbije; Studija priključenja VE Kovačica na prenosni sistem Srbijesistemske analize, Studija, Beograd 2015

\section{Kratka biografija:}

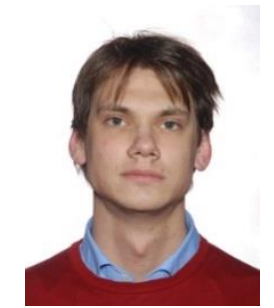

David Ivanović, rođen je u Zrenjaninu 1993. godine, završio je osnovne studije na Fakultetu tehničkih nauka 2017. godine iz oblasti Elektrotehnike i računarstva - Elektroenergetski sistemi. Master rad na istom fakultetu smer Elektroenergetika - Elektroenergetski sistemi odbranio je 2019. godine. 